\title{
Роль С-реактивного белка в диагностике бактериальной инфекции и пневмонии у пациентов с обострением хронической обструктивной болезни легких
}

ФГУ "НИИ пульмонологии ФМБА России": 105077, Москва, ул. 11-я Парковая, 32, к. 4

\author{
S.N.Avdeev, G.E.Baimakanova, P.A.Zubairova, A.G.Chuchalin
}

\begin{abstract}
Summary
The purpose of this study was to assess the performance of a rapid bedside whole blood test of C-reactive protein (CRP) for diagnosis of bacterial infection and pneumonia in patients with acute exacerbation of COPD (AE COPD). One hundred and twenty three patients with AE COPD admitted to a hospital (mean age $65.4 \pm 48.8$ years, smoking history $42.8 \pm 14.3$ packs-years) were studied. CRP concentration was determined by using the finger-stick blood test (NycoCard II Test Kit). Patients with AE COPD were divided into three groups according to the sputum purulence and appearance of radiographic pneumonic infiltrates: 1) AE COPD with pneumonia; 2) AE COPD with mucoid sputum; 3) AE COPD with purulent sputum. In the study, 23 patients had radiographic evidence of pneumonia. The mean CRP in this group was $105.8 \pm 66.1 \mathrm{mg} / \mathrm{L}$ and was significantly higher than that in AE COPD patients without pneumonia $(p<0.001)$. Patients with AE COPD and mucoid sputum $(n=26)$ had mean CRP $12.1 \pm 7.0 \mathrm{mg} / \mathrm{L}$ that was significantly lower when compared to the patients with purulent sputum $(n=74$; mean CRP $34.5 \pm 18.8 \mathrm{mg} / \mathrm{L} ; p<0.001)$. A rapid bedside whole blood CRP test is a useful tool for diagnosis of bacterial infection and pneumonia in patients with AE COPD. It may be used as a guide for administration of empiric antibacterial therapy in AE COPD patients.

Key words: C-reactive protein, acute exacerbation of COPD, pneumonia, bacterial infection.
\end{abstract}

\section{Резюме}

Целью исследования было изучение роли С-реактивного белка (СРБ) в диагностике бактериальных инфекций и пневмонии при обострении хронической обструктивной болезни легких (ХОБЛ). Были обследованы 123 пациента (средний возраст $-65,4 \pm 48,8$ года, индекс курения - 42,8 $\pm 14,3$ пачки / лет), госпитализированных в стационар с обострением ХОБЛ. Уровень СРБ в крови измеряли с помощью системы NycoCard II Test Kit (Axis-Shield, Норвегия). У 23 больных с обострением ХОБЛ диагностирована пневмония. Концентрация сывороточного СРБ у больных пневмонией была выше, чем у пациентов без пневмонии $(105,8 \pm 66,1$ мг/л; $p<0,001)$. У пациентов без продукции гнойной мокроты $(n=26)$ уровень СРБ был ниже, чем у больных с продукцией гнойной мокроты $(n=74): 12,1 \pm 7,0$ мг/л $v s 34,5 \pm 18,8$ мг/л $(p<0,001)$. СРБ является ценным маркером бактериальной инфекции и пневмонии у больных с обострением ХОБЛ, что важно для разработки тактики лечения данной категории пациентов.

Ключевые слова: обострение хронической обструктивной болезни легких, С-реактивный белок, пневмония, бактериальные инфекции.

Хроническая обструктивная болезнь легких (ХОБЛ) является одной из ведущих причин заболеваемости и летальности в современном обществе. Эта патология занимает 4-е место среди всех причин смерти в общей популяции, что составляет $\sim 4 \%$ в структуре общей летальности [1].

Развитие обострений является характерной чертой течения ХОБЛ, их частота прогрессивно увеличивается с нарастанием тяжести заболевания. Обострения ХОБЛ часто ассоциируются с клинической и лабораторно подтвержденной инфекцией бронхиального дерева [2, 3]. В то же время у пациентов с тяжелым обострением ХОБЛ не всегда присутствует продукция мокроты [4], трактовка микробиологического анализа мокроты часто затруднена [5], и нередко невозможно исключить пневмонию на основании данных рентгенографии, что объясняется сложностью интерпретации результатов клинических и параклинических методов исследования у данной группы больных.
Кроме того, ХОБЛ считают фактором риска внебольничной пневмонии (ВП) [6-8]. Диагностировать пневмонию у больных с обострением ХОБЛ, а особенно с острой дыхательной недостаточностью и сложным коморбидным фоном, непросто. Обычные клинические и лабораторные критерии пневмонии (лихорадка, усиление диспноэ, кашель, продукция гнойной мокроты, лейкоцитоз и др.) довольно неспецифичны и, кроме того, укладываются в картину собственно обострения ХОБЛ. В связи с этим представляет особый интерес поиск информативных маркеров для подтверждения клинически значимой бактериальной инфекции у больных ХОБЛ. Одним из них является С-реактивный белок (СРБ) $[9,10]$. Доказана высокая диагностическая ценность экспресс-теста СРБ у пациентов с ВП [11].

Целью настоящего исследования явилось изучение роли биомаркеров воспаления - СРБ, интерлейкина-6 (IL-6), фактора некроза опухоли- $\alpha$ (TNF- $\alpha$ ) у госпитализированных больных с обострением 
ХОБЛ. Сравнивались группы пациентов с обострением ХОБЛ в зависимости от наличия пневмонии, тяжести обострения и степени гнойности мокроты.

\section{Материалы и методы}

По дизайну исследование было открытым проспективным.

Критерии включения пациентов в исследование были следующими:

- подтвержденный диагноз ХОБЛ [1];

- возраст $\geq 45$ лет;

- анамнез курения $\geq 20$ пачек / лет;

- наличие $\geq 2$ критериев Anthonisen (усиление одышки, увеличение продукции мокроты, увеличение гнойности мокроты) [12].

Критериями исключения являлись:

- другие хронические и острые заболевания легких (астма, диффузные бронхоэктазы, облитерирующий бронхиолит, тромбоэмболия легочной артерии или ее ветвей, пневмоторакс и др.);

- тяжелые сопутствующие соматические и инфекционные заболевания в стадии декомпенсации (инфаркт миокарда, нестабильная стенокардия, застойная сердечная недостаточность);

- опухоли;

- травмы, ожоги в предшествующие 7 дней;

- диффузные заболевания соединительной ткани (ревматоидный артрит и др.).

В ходе исследования все пациенты с обострением ХОБЛ были разделены на 3 группы: с продукцией слизистой мокроты, с продукцией гнойной мокроты и наличием пневмонии. По данным проведенных исследований, гнойная мокрота у больных с обострением ХОБЛ является признаком бактериальной инфекции, аккуратность данного признака составляет $90 \%$ [13]. Пневмония при обострении ХОБЛ определялась как появление "новых" инфильтративных затемнений на рентгенограмме грудной клетки и наличие симптомов инфекционного заболевания нижних дыхательных путей (лихорадка, лейкоцитоз, кашель, продукция гнойной мокроты, усиление диспное, "плевритические" боли в грудной клетке [7].

У всех больных оценивались демографические показатели, стаж курения, индекс массы тела, симптомы и физикальные признаки, общая тяжесть состояния, рентгенография грудной клетки, общий и биохимический анализ крови, наличие сопутствующих заболеваний, предшествующая терапия, число госпитализаций в течение последнего года, число случаев пневмонии за 3 года. При необходимости проводилась компьютерная томография легких или бронхоскопия.

В 1-е сут. поступления в стационар выполняли бактериологическое исследование мокроты. Материалом для него служила мокрота, полученная после глубокой экспекторации, или бронхоальвеолярный лаваж. Порция мокроты окрашивалась по Граму, после чего под малым увеличением проводился подсчет эпителиальных клеток и лейкоцитов. Только образцы мокроты, удовлетворяющие критериям Murray-Washington (< 10 эпителиальных клеток и $>25$ лейкоцитов в поле зрения; $\times 100)$ исследовали на культуры микроорганизмов [14]. Диагностически значимой считали концентрацию колониеобразующихся единиц $>10^{6}$ ммл, для Streptococcus pneumoniae - 105/л. Чувствительность изолятов к антибактериальным препаратам определяли посредством диско-диффузионного метода, согласно рекомендациям Clinical and Laboratory Standards Institute [15].

Образцы сыворотки крови были отобраны для определения СРБ, IL-6 и TNF- $\alpha$. Уровень СРБ в сыворотке крови измеряли иммунометрическим методом с помощью системы NycoCard II Test Kit (AxisShield, Норвегия). Концентрацию в сыворотке крови IL-6, TNF- $\alpha$ выявляли на оборудовании Tecan Sunrise (Tecan Trading AG, Щвейцария) с использованием иммуноферментных наборов для количественного определения биомаркеров фирмы Biosource (Бельгия).

Статистическая обработка результатов была проведена при помощи пакета прикладных программ SPSS 13 for Windows. Все численные данные представлены как mean $\pm S D$ или медиана (Me) с 2575\%-ным интерквартильным размахом (IQR). Достоверность различий одноименных количественных показателей внутри группы определялась с помощью критерия Вилкоксона, между группами посредством U-критерия Манна-Уитни и Крускала-Уоллиса, качественные различия между группами - с помощью точного теста Фишера. Различия считались статистически достоверными при $p<0,05$. Чтобы определить ценность СРБ в диагностике пневмонии при ХОБЛ, использовали ROC-анализ.

\section{Результаты}

В исследовании приняли участие 123 пациента (из них 113 мужчин и 10 женщин; средний возраст $65,4 \pm 48,8$ года, индекс курения $-42,8 \pm 14,3$ пачки / лет), госпитализированных в стационар с обострением ХОБЛ. Преобладали больные с тяжелым и крайне тяжелым течением ХОБЛ (табл. 1). У 23 пациентов с ХОБЛ диагностирована ВП, без продукции гнойной мокроты обострение ХОБЛ протекало у 26 больных, и наиболее многочисленную группу составили пациенты с продукцией гнойной мокроты (74 человека). Среди сопутствующей патологии у больных ХОБЛ преобладали ишемическая болезнь сердца $(82,1 \%)$, артериальная гипертония (80,5\%) и цереброваскулярная болезнь $(56,1 \%)$.

На момент госпитализации постоянно принимали ингаляционные глюкокортикостероиды (иГКС) 67 больных $(54,5 \%)$, системные глюкокортикостероиды (сГКС) - 15 пациентов (12,2\%) и 17 человек $(13,8 \%)$ применяли иГКС эпизодически. Домашнюю оксигенотерапию получали 13 больных (10,1\%). В условиях стационара неинвазивная вентиляция легких проводилась 12 больным (9,8 \%), искусственная вентиляция легких - 2 пациентам $(2,7 \%)$. 
Характеристика пациентов с обострением ХОБЛ

\begin{tabular}{|c|c|c|c|c|c|c|}
\hline Параметры & $\begin{array}{c}\text { Обострение ХОБЛ } \\
\text { без гнойной мокроты }\end{array}$ & $\begin{array}{l}\text { Обострение ХОБЛ } \\
\text { с гнойной мокротой }\end{array}$ & $\begin{array}{c}\text { Обострение ХОБЛ } \\
\text { и ВП }\end{array}$ & & $p$ & \\
\hline Группа & 1-я & 2-я & 3-я & $p_{1-2}$ & $p_{1-3}$ & $p_{2-3}$ \\
\hline Пол, м / ж & $26 / 0$ & $65 / 9$ & $22 / 1$ & 0,107 & 0,469 & 0,443 \\
\hline Средний возраст, лет & $64,9 \pm 8,7$ & $65,4 \pm 8,5$ & $65,9 \pm 10,3$ & 0,620 & 0,688 & 0,915 \\
\hline ИМТ, кг/м² & $24,9 \pm 8,1$ & $26,6 \pm 9,8$ & $27,9 \pm 6,3$ & 0,380 & 0,047 & 0,174 \\
\hline Индекс курения, пачек / лет & $44,8 \pm 14,5$ & $43,5 \pm 15,1$ & $38,3 \pm 10,3$ & 0,981 & 0,118 & 0,108 \\
\hline Длительность ХОБЛ, лет & $10,7 \pm 5,4$ & $11,2 \pm 5,4$ & $7,5 \pm 5,6$ & 0,713 & 0,028 & 0,003 \\
\hline Частота обострений в год & $2,5 \pm 1,1$ & $3,1 \pm 0,9$ & $2,2 \pm 1,0$ & 0,017 & 0,176 & $<0,001$ \\
\hline
\end{tabular}

Примечание: $p_{1-2}$ - между 1-й и 2-й группами; $p_{1-3}$ - между 1-й и 3-й группами; $p_{2-3}$ - между 2-й и 3-й группами; ИМТ - индекс массы тела.

Более $1 / 2$ больных $(54,5 \%)$ связывали обострение ХОБЛ с перенесенной вирусной инфекцией. Тяжесть обострения, по критериям Anthonisen, была больше выражена в группах больных с продукцией гнойной мокроты и пневмонией $(p<0,001)$.

Возбудители ВП и бактериального обострения ХОБЛ перечислены в табл. 2. При пневмонии возбудители идентифицированы в 47,8 \%, при бактериальном обострении ХОБЛ - в 41,0 \% случаев. Доминирующим этиологическим агентом при пневмонии был S. pneumoniae $(21,7 \%)$. При "непневмоническом" обострении ХОБЛ чаще других высевалась Pseudomonas aeruginosa $(13 \%)$, затем - S. pneumoniae (9\%), Acinetobacter spp. (5\%), Stenotrophomonas maltophilia (4\%) и Staphylococcus aureus (3\%), остальные возбудители встречались реже.

Концентрация сывороточного СРБ у больных ХОБЛ с ВП была значительно выше, чем у пациентов с обострением ХОБЛ, сопровождавшимся про-

Таблица 2

Этиологическая структура инфекционного обострения ХОБЛ

\begin{tabular}{|l|c|c|}
\multicolumn{1}{c|}{ Возбудитель } & $\begin{array}{c}\text { Обострение } \\
\text { ХОБЛ без ВП, } n(\%)\end{array}$ & $\begin{array}{c}\text { Обострение } \\
\text { ХОБЛ и ВП, } n(\%)\end{array}$ \\
\hline S. pneumoniae & $9(9,0)$ & $5(21,7)$ \\
\hline Haemophilus influenzae & $2(2,0)$ & - \\
\hline Klebsiella pneumoniae & $1(1,0)$ & $2(8,6)$ \\
\hline S. aureus & $3(3,0)$ & $2(8,6)$ \\
\hline Moraxella catarrhalis & $1(1,0)$ & - \\
\hline P. aeruginosa & $13(13,0)$ & $1(4,3)$ \\
\hline Acinetobacter spp. & $5(5,0)$ & $1(4,3)$ \\
\hline Stenotrophomonas maltophilia & $4(4,0)$ & - \\
\hline Enterobacter spp. & $2(2,0)$ & - \\
\hline Borhordelia spp. & $1(1,0)$ & - \\
\hline
\end{tabular}

дукцией гнойной и слизистой мокроты: $105,8 \pm 66,1$ vs $34,5 \pm 18,8$ vs $12,1 \pm 7,0$ мг/л соответственно ( $p<0,001$; табл. 3 ; рис. 1$)$. У 42,3 \% пациентов без увеличения гнойности мокроты уровень СРБ был нормальным, у больных с продукцией гнойной мокроты нормальное значение СРБ было зарегистрировано лишь у $5,4 \%$. У пациентов без гнойной мокроты уровень СРБ был ниже, чем у больных с продукцией гнойной мокроты $(12,1 \pm 7,0$ мг/л $v s$ $34,5 \pm 18,8$ мг/л; $p<0,001)$. Сывороточный уровень IL-6 и TNF- $\alpha$ был значительно выше у больных с BП, чем у пациентов с обострением ХОБЛ и продукцией слизистой ( $p=0,024$ и 0,010 соответственно) и гнойной мокроты ( $p=0,027$ и 0,013 соответственно). Число лейкоцитов крови было также достоверно выше у больных ХОБЛ с ВП $(p=0,041)$.

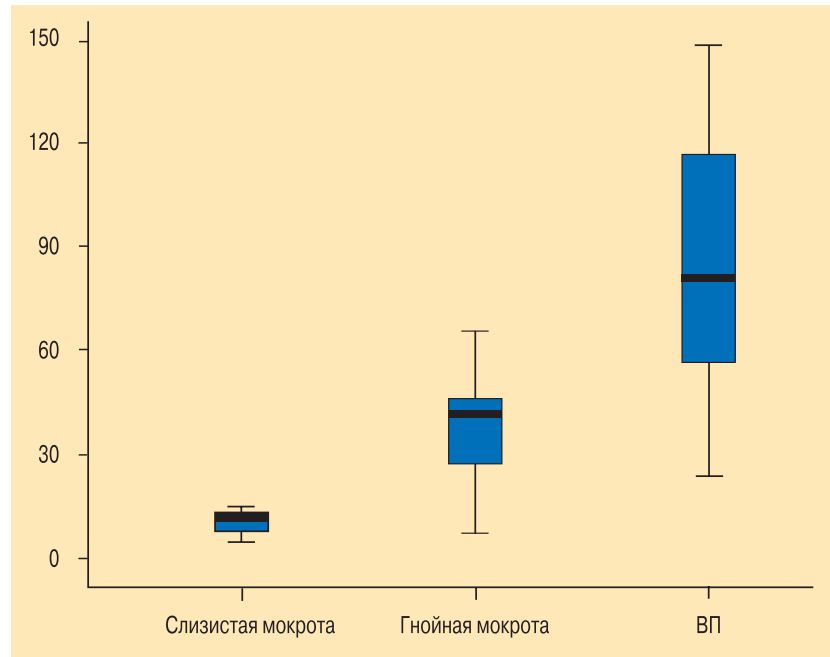

Рис. 1. Уровни СРБ при обострении ХОБЛ со слизистой мокротой, с продукцией гнойной мокроты и с ВП $(p<0,001)$

Таблица 3

Биомаркеры воспаления при обострении ХОБЛ

\begin{tabular}{|c|c|c|c|c|c|c|}
\hline Параметры & $\begin{array}{c}\text { Обострение ХОБЛ } \\
\text { без гнойной мокроты }\end{array}$ & $\begin{array}{l}\text { Обострение ХОБЛ } \\
\text { с гнойной мокротой }\end{array}$ & $\begin{array}{c}\text { Обострение ХОБЛ } \\
\text { и ВП }\end{array}$ & & $p$ & \\
\hline Группа & 1-я & 2-я & 3-я & $p_{1-2}$ & $p_{1-3}$ & $p_{2-3}$ \\
\hline Лейкоциты крови, 109/л & $9,7 \pm 2,4$ & $9,5 \pm 2,8$ & $11,8 \pm 4,9$ & 0,443 & 0,266 & 0,041 \\
\hline СРБ, мг/л & $12,1 \pm 7,0$ & $34,5 \pm 18,8$ & $105,8 \pm 66,1$ & $<0,001$ & $<0,001$ & $<0,001$ \\
\hline IL-6, пг/мл & $2,01(1,9-4,6)$ & $9,1(6,3-48,1)$ & $110,1(7,4-416,9)$ & 0,351 & 0,024 & 0,010 \\
\hline TNF- $\alpha$, пг/мл & $2,5(2,3-5,3)$ & $2,8(1,5-6,6)$ & $8,7(15,2-185,1)$ & 0,726 & 0,027 & 0,013 \\
\hline
\end{tabular}

Примечание: $p_{1-2}$-между 1-й и 2-й группами; $p_{1-3}$ - между 1-й и 3-й группами; $p_{2-3}$-между 2-й и 3-й группами. 


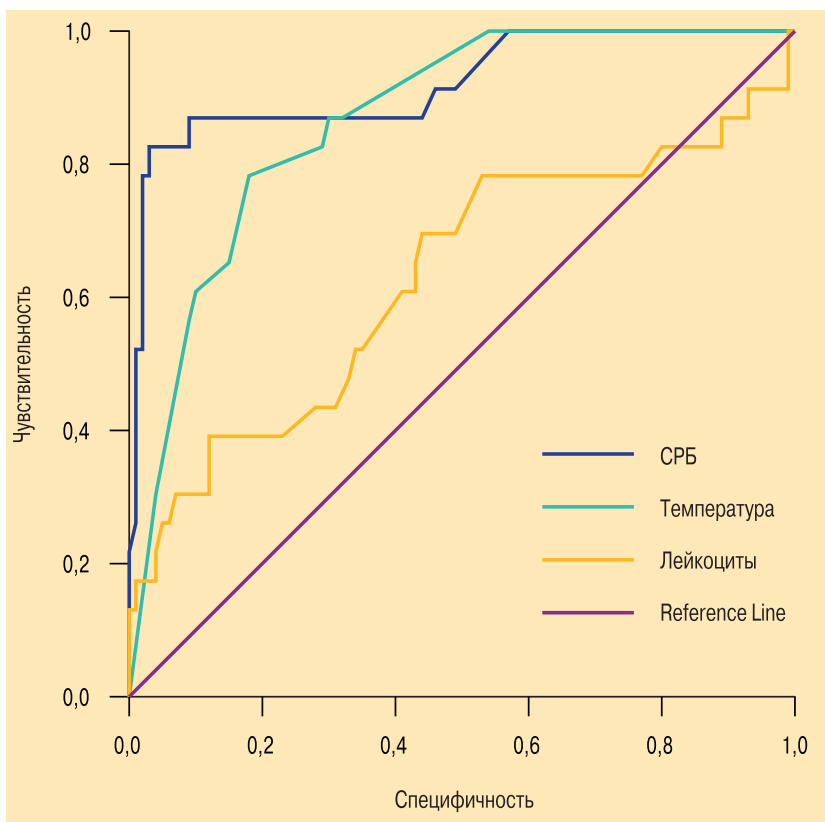

Рис. 2. ROC-кривая оценки значения параметров (СРБ, температура тела и лейкоциты крови) для диагностики пневмонии у больных ХОБЛ

У пациентов с ВП и без нее и у тех больных, которых прежде лечились ГКС, уровень лейкоцитов крови имел тенденцию к увеличению (табл. 4), однако у больных без ВП различия не были статистически значимы. Не выявлено достоверных различий по уровню СРБ у пациентов, получавших и не получавших иГКС и сГКС, но у больных ВП уровень лейкоцитов крови был выше $(p<0,05)$.

ROC-анализ показал, что сывороточный уровень СРБ является наиболее ценным и достоверным признаком наличия ВП у больных ХОБЛ, по сравнению с другими воспалительными маркерами (температурой тела и лейкоцитозом периферической крови, IL-6 и TNF- $\alpha$ ), - эти данные представлены в табл. 4. Площадь под кривой ROC для СРБ была равна 0,921 ( $p<0,001 ; 95 \%$-ный доверительный интервал (ДИ) - 0,850-0,992), как показано на рис. 2. Пороговый уровень СРБ $\geq 51,5$ мг/л для диагностики ВП у больных ХОБЛ имел чувствительность $87 \%$, специфичность - $91 \%$, позитивную предиктивную ценность (ППЦ) - 68,8 \%, негативную предиктивную ценность (НПЦ) - 96,8 \% (табл. 5). Меньшую, но значимую диагностическую ценность имели также TNF- $\alpha$ и IL-6.

Площадь под ROC-кривой для СРБ как парамет$\mathrm{pa}$, способного указывать на наличие бактериальной инфекции при обострении ХОБЛ, составила 0,932

Таблица 5

Информативность показателя СРБ для диагностики ВП у больных ХОБЛ

\begin{tabular}{|l|c|c|c|c|}
\hline СРБ, мг/л & $\begin{array}{c}\text { Чувстви- } \\
\text { тельность }\end{array}$ & Специфичность & ППц & НПЦ \\
\hline$\geq 30$ & 0,870 & 0,650 & 0,362 & 0,956 \\
\hline$\geq 40$ & 0,870 & 0,730 & 0,424 & 0,961 \\
\hline 250 & 0,870 & 0,910 & 0,688 & 0,968 \\
\hline$\geq 75$ & 0,739 & 0,980 & 0,894 & 0,942 \\
\hline$\geq 100$ & 0,391 & 0,990 & 0,899 & 0,876 \\
\hline
\end{tabular}

( $p<0,001$; 95\%-ный ДИ - 0,867-0,996; рис. 3). Пороговый уровень СРБ $\geq 16,5$ мг/л для диагностики бактериальной инфекции при обострении ХОБЛ имел чувствительность 93,1 \%, специфичность 93,2 \%, ППЦ - 97,1\%, НПЦ - 82,3 \% (табл. 6).

Уровень биомаркеров воспаления у больных ХОБЛ без ВП при позитивном и отрицательном результатах посева мокроты статистически не различался (табл. 7).

\section{Обсуждение}

Проведенное исследование показало, что концентрация СРБ в сыворотке крови у больных с инфекционным обострением ХОБЛ (т. е. с продукцией гной-

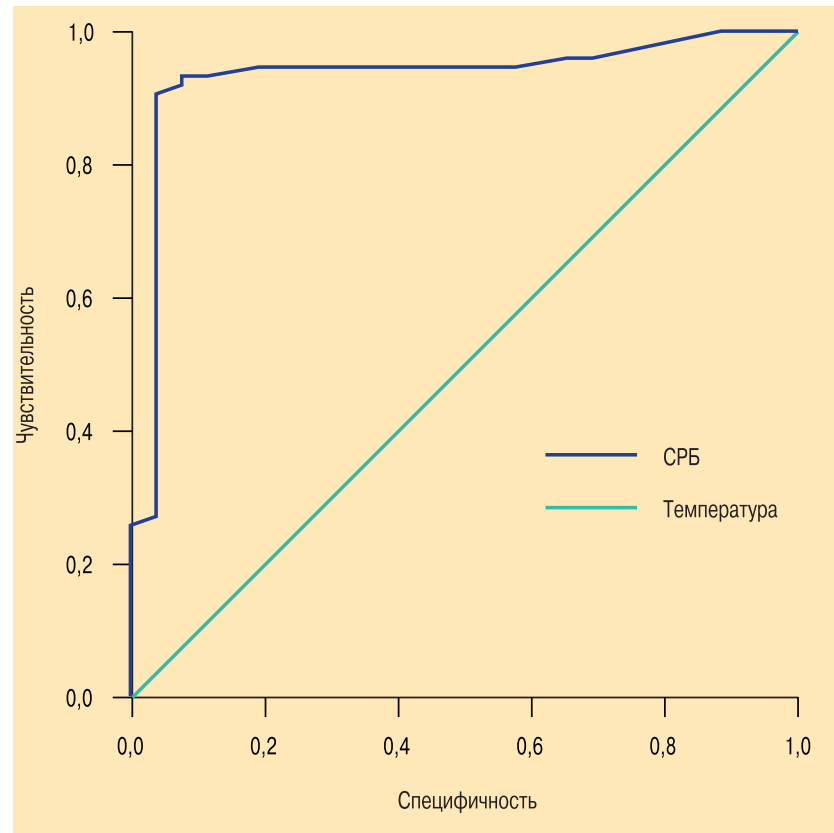

Рис. 3. ROC-кривая оценки значения параметра СРБ для диагностики бактериальной инфекции при обострении ХОБЛ

Таблица 4

Диагностическая ценность маркеров воспаления для ВП у пациентов с ХОБЛ

\begin{tabular}{|c|c|c|c|c|c|c|}
\hline Параметр & Площадь под кривой ROC & $p$ & 95\%-ный ди & Пороговый уровень & Чувствительность & Специфичность \\
\hline СРБ, мг/л & 0,921 & $<0,001$ & $0,850-0,992$ & 51,5 & 0,870 & 0,910 \\
\hline $\mathrm{t},{ }^{\circ} \mathrm{C}$ & 0,867 & $<0,001$ & $0,796-0,937$ & 37,3 & 0,870 & 0,700 \\
\hline $\begin{array}{l}\text { Лейкоциты крови, } \\
\times 10^{9} \text { клеток / л }\end{array}$ & 0,629 & 0,055 & $0,485-0,772$ & 9,1 & 0,739 & 0,490 \\
\hline IL-6, пг/мл & 0,734 & 0,003 & $0,555-0,913$ & 7,02 & 0,833 & 0,500 \\
\hline TNF- $\alpha$, пг/мл & 0,801 & 0,006 & $0,637-0,965$ & 4,6 & 0,833 & 0,722 \\
\hline
\end{tabular}


Таблица 6 Информативность СРБ для диагностики бактериальной инфекции при обострении ХОБЛ

\begin{tabular}{|l|c|c|c|c|}
\hline СРБ, мг/л & $\begin{array}{c}\text { Чувстви- } \\
\text { тельность }\end{array}$ & Специфичность & ППЦ & НПЦ \\
\hline$\geq 10$ & 0,946 & 0,423 & 0,823 & 0,733 \\
\hline$\geq 15$ & 0,932 & 0,923 & 0,971 & 0,823 \\
\hline 20 & 0,878 & 0,962 & 0,985 & 0,734 \\
\hline 25 & 0,649 & 0,962 & 0,979 & 0,491 \\
\hline 30 & 0,486 & 0,962 & 0,973 & 0,336 \\
\hline
\end{tabular}

ной мокроты) была значительно выше, чем у пациентов со слизистой мокротой, и наиболее выраженное увеличение СРБ было зарегистрировано у пациентов с обострением ХОБЛ и пневмонией. У $42,3 \%$ больных с обострением ХОБЛ без гнойной мокроты уровень СРБ был нормальным, при этом у пациентов с продукцией гнойной мокроты нормальное значение СРБ было выявлено лишь в 5,4 \% случаев.

По данным ROC-анализа, сывороточный уровень СРБ, по сравнению с другими воспалительными маркерами (лейкоцитозом периферической крови, сывороточными концентрацией IL-6 и TNF- $\alpha$ ), являлся наиболее ценным и достоверным признаком наличия бронхиальной инфекции и ВП при обострении ХОБЛ. При обострении ХОБЛ чувствИтельность порогового уровня СРБ $\geq 16,5$ мг/л для диагностики бактериальной инфекции составила $93 \%$, а специфичность - $93 \%$, чувствительность порогового уровня СРБ $\geq 51,5$ мг/л $-87 \%$, а специфичность $-91 \%$.

Как известно, наиболее частой причиной обострения ХОБЛ является бактериальная инфекция [5, 13]. При диагностике инфекционного обострения ХОБЛ иногда невозможно исключить пневмонию на основании только рентгенографических методов [13]. Это объясняется трудностями интерпретации результатов клинических и параклинических методов исследования у данной группы больных.

О ценности СРБ как биомаркера обострения ХОБЛ свидетельствуют результаты исследования J.R.Hurst et al., в котором проводилось сравнение чувствительности и специфичности 36 различных биомаркеров у 90 пациентов с обострением ХОБЛ [16]. Оказалось, что, по сравнению со всеми изученными маркерами, наибольшей диагностической ценностью обладал хорошо известный СРБ. Для данного биомаркера площадь под ROC-кривой составила 0,73, а при сочетании повышения СРБ и одного из "больших" критериев Anthonisen обострения ХОБЛ

Таблица 7

Значение биомаркеров воспаления в зависимости от результатов бактериологического посева мокроты у больных ХОБЛ без ВП

\begin{tabular}{l|c|c|c} 
Параметр & $\begin{array}{c}\text { Положительный } \\
\text { результат посева }\end{array}$ & $\begin{array}{c}\text { Отрицательный } \\
\text { результат посева }\end{array}$ & $p$ \\
\hline CP5, мг/л & $34,5(21,0-56,0)$ & $26,0(18,5-44,0)$ & 0,071 \\
IL-6, пг/м & $6,9(3,4-13,7)$ & $7,9(3,2-116,0)$ & 0,438 \\
\hline TNF- $\alpha$, пr/мл & $3,5(2,2-8,8)$ & $5,2(2,7-9,3)$ & 0,757
\end{tabular}

(усиления одышки, объема мокроты или гнойности мокроты) площадь под ROC-кривой равнялась 0,88 . В данном исследовании не было установлено связи между уровнем повышения СРБ и степенью тяжести обострения ХОБЛ.

В работе D.Dev et al. уровень СРБ > 10 мг/л был зарегистрирован у всех больных с доказанным инфекционным обострением ХОБЛ (среднее значение $-103 \pm 98$ мг/л) [9], причем концентрация СРБ значительное повышалась при обострении пневмококковой этиологии (156 мг/л). Сывороточный уровень СРБ коррелировал с лейкоцитозом периферической крови $(r=0,44 ; p<0,01)$ и снижался на фоне лечения антибиотиками.

Предполагается, что при обострении хронического бронхита или ХОБЛ СРБ повышается в меньшей степени, чем при пневмонии. R.P.Smith et al. в ретроспективном анализе обнаружили низкую концентрацию СРБ (18 \pm 3 мг/л) у 20 пациентов с гнойным бронхитом, по сравнению с 40 больными ВП $(217 \pm 16$ мг/л) [17].

В недавно проведенном исследовании D.Justo et al. сравнивали скорость изменения СРБ у 36 больных с обострением ХОБЛ и у 49 пациентов с ВП [18]. Различие в исходной (т. е. зарегистрированной при поступлении в стационар) концентрации СРБ между группами было значительным: 111,5 \pm 104,4 мг/л vs 34,9 $\pm 28,6$ мг/л (соответственно у больных ВП и ХОБЛ; $p<0,0001)$. Интересно, что на следующий день после назначения антибактериальной терапии уровень СРБ снизился в среднем на 36,7 \% у пациентов с ВП и всего на 5,9\% - у больных с обострением ХОБЛ $(p=0,005)$.

$N$.Weis et al. изучали диагностическую ценность теста СРБ у 166 госпитализированных пациентов с обострением ХОБЛ [19], у которых имелись большие колебания уровня СРБ, включая и нормальные значения. Пневмония была диагностирована у 51 больного, уровень СРБ у них соответствовал $M е 97$ мг/л (IQR - 49-145 мг/л). Пациенты без пневмонии (46 \%) имели нормальный уровень СРБ (0-10 мг/л). У 64 больных без увеличения гнойности мокроты СРБ был равен 8 мг/л (IQR - 2,9-16,0 мг/л), что было значительно ниже, чем у пациентов с гнойной мокротой (45 мг/л; IQR - 8,5-86,0 мг/л; $p<0,001)$. Низкое значение СРБ регистрировалось у пациентов, соответствующих критериям Anthonisen III, по сравнению с теми, которые имели 2 и 3 критерия тяжести обострения. Также было установлено, что уровень СРБ не зависел от применения в комплексной терапии ГКС.

В работе A.Bircan et al. были получены данные, сходные с результатами настоящего исследования: максимальное значение сывороточного уровня СРБ было выявлено у больных с обострением ХОБЛ и ВП $(108,1 \pm 61,8$ мг/л), менее выраженное повышение СРБ сопровождало обострение ХОБЛ без ВП (36,8 \pm 43,9 мг/л), причем у больных с гнойной мокротой СРБ сыворотки был достоверно выше, по сравнению с пациентами с продукцией слизистой мокроты $(46,4 \pm 48,6$ vs 28,0 \pm 44,5 мг/л; $p=0,015)$ [20]. 
Изменение уровня СРБ у больных с обострением ХОБЛ [10]

\begin{tabular}{|c|c|c|c|c|c|c|}
\hline \multirow[t]{2}{*}{ Исследование } & \multirow[t]{2}{*}{$n$} & \multirow[t]{2}{*}{$0 \Phi B_{1}$} & \multicolumn{4}{|c|}{ Концентрации СРБ, мг/л } \\
\hline & & & 1-й день & 5-7-й дни & 12-14-й дни & 28-35-й дни \\
\hline D.Dev et al., 1998 г. [9] & 50 & $0,8 \pm 0,4$ л & $103 \pm 98$ & $33 \pm 4$ & & \\
\hline $\begin{array}{l}\text { W.J.C.van Beurden et al., } \\
2003 \text { г. [21] }\end{array}$ & 19 & $39,8 \pm 3,0 \%$ ** & $84,5 \pm 21,5^{\star *}$ & $20,1 \pm 6,7^{\star *}$ & & \\
\hline M.A.Spruit et al., 2003 r. [22] & 34 & $40 \pm 17 \%$ & 28 [11-86] & 11,3 & & \\
\hline W.R.Perera et al., 2007 r. [26] & 73 & $45 \pm 18 \%$ & $10,9[5,5-34,2]$ & $5,3[3,5-9,4]$ & $4,0[2,3-9,6]$ & $6,8[3,6-11,6]$ \\
\hline D.Stolz et al., 2007 r. [23] & $\begin{array}{l}102^{1} \\
106^{2}\end{array}$ & $\begin{array}{l}0,85 \pm 0,32 \pi \\
0,99 \pm 0,48 \pi\end{array}$ & $\begin{array}{l}32 \pm 42 \\
44 \pm 55\end{array}$ & $\begin{array}{l}10 \pm 21 \\
18 \pm 27\end{array}$ & & \\
\hline D.Stolz et al., 2007 г. [24] & 167 & $39,9 \pm 16,9 \%$ & $26,5[7,4-60,1]$ & & $7,5[2-19,5]$ & \\
\hline R.A.Stockley et al., 2000 r. [13] & $87^{*}$ & $61,1 \pm 22,4^{*}$ & $14,5[6,2-35,8]^{*}$ & & $2,7[1,0-4,9]^{*}$ & \\
\hline G.Nuralieva et al., 2007 r. [25] & 26 & $28,4 \pm 10,3 \%$ & $27,2 \pm 13,6$ & & $18,3 \pm 10,4$ & $14,8 \pm 9,0$ \\
\hline
\end{tabular}

Примечание: ОФВ 1 - объем форсированного выдоха за 1-ю с; ${ }^{*}$ - обострение ХОБЛ с гнойной мокротой; ** - теап \pm SEM; ${ }^{1}$ - группа стандартной терапии; ${ }^{2}$ - группа терапии на основе измерений прокальцитонина

Чувствительность и специфичность СРБ для диагностики бактериального обострения ХОБЛ составили соответственно $72,5 \%$ и $100 \%$.

К достоинствам СРБ как маркера обострения ХОБЛ относится его сравнительно быстрый уровень возвращения к предыдущим значениям по мере разрешения обострения. В табл. 8 представлены данные 8 исследований, в которых приводились сведения о динамике изменений СРБ в течение 35 дней после развития обострения [9, 13, 21-26]. Кроме того, особенности снижения СРБ у больных ХОБЛ могут указывать на возможность рецидива обострения. В исследовании W.R.Perera et al. проводилось изучение сывороточной концентрации СРБ у 73 больных ХОБЛ в стабильный период, во время развития обострения и на 7-й, 14-й и 35-й дни после обострения [26]. У 23 \% пациентов даже к 35-му дню наблюдения выраженность симптомов заболевания не снизилась до исходного уровня (т. е. до состояния перед обострением). У данных больных также не уменьшился и сывороточный уровень СРБ. Кроме того, у 22 \% пациентов, у которых в течение ближайших 50 дней развивалось повторное обострение (рецидив), отмечалась более высокая концентрация СРБ на 14-й день после обострения - 8,8 мг/л vs 3,4 мг/л.

Полученные данные свидетельствуют о роли СРБ как маркера активной бактериальной инфекции при обострении ХОБЛ, что важно для решения вопроса о назначении антибактериальной терапии. Это особенно актуально при отсутствии методов верификации клинически значимой инфекции у больных ХОБЛ.

\section{Заключение}

1. СРБ является чувствительным и специфичным маркером в диагностике бактериальной инфекции и ВП у больных ХОБЛ.

2. Пороговое значение СРБ для диагностики бактериальной инфекции у больных с обострением ХОБЛ составляет $\geq 16,5$ мг/л (чувствительность $93 \%$, специфичность - $93 \%$ ).
3. Пороговое значение СРБ для диагностики ВП у больных ХОБЛ составляет $\geq 51,5$ мг/л (чувствительность $-87 \%$, специфичность - $91 \%$ ).

4. Определение СРБ является полезным тестом для скрининга и подтверждения активного инфекционного обострения ХОБЛ (пневмонии, гнойного бронхита), что важно для разработки тактики лечения данной категории больных.

\section{Литература}

1. Global Initiative for Chronic Obstructive Lung Disease (GOLD). Global strategy for diagnosis, management, and prevention of chronic obstructive pulmonary disease. NHLBI / WHO workshop report. The 2008 report is available on www.goldcopd.com.

2. Celli B.R., Barnes P.J. Exacerbation of chronic obstructive pulmonary disease. Eur. Respir. J. 2007; 29: 1224-1238.

3. Sethi S., Murphy T.F. Infection in the pathogenesis and course of chronic obstructive Ppulmonary disease. N. Engl. J. Med. 2008; 359: 2355-2365.

4. Pinto-Plata V.M., Livnat G., Girish M. et al. Systemic cytokines, clinical and physiological changes in patients hospitalized for exacerbation of COPD. Chest 2007; 131: 37-43.

5. Fagon J.Y., Chastre J., Trouillet J.L. et al. Characterization of distal bronchial microflora during acute exacerbation of chronic bronchitis: use of the protected specimen brush technique in 54 mechanically ventilated patients. Am. Rev. Respir. Dis. 1990; 142: 1004-1008.

6. Авдеев С.Н., Баймаканова Г.Е., Зубаирова П.А., Чучалин А.Г. Пневмония как причина острой дыхательной недостаточности у больных ХОБЛ. Пульмонология 2006; 5: 115-121.

7. Farr B.M., Kaiser D.L., Harrison B.D., Connolly C.K. Prediction of microbial aetiology at admission to hospital for pneumonia from the presenting clinical features. British Thoracic Society Pneumonia Research Subcommittee. Thorax 1989; 44: 1031-1035.

8. Баймаканова Г.Е., Зубаирова П.А., Авдеев С.Н., Чучалин А.Г. Особенности клинической картины и течения внебольничной пневмонии у пациентов с хронической обструктивной болезнью легких. Пульмонология 2009; 2: 33-41.

9. Dev D., Sankaran E.W.R., Cunnife J. et al. Value of C-reactive protein in exacerbation of chronic obstructive pulmonary disease. Respir. Med. 1998; 92: 664-667. 
10. Авдеев С.Н., Баймаканова Г.Е. С-реактивный белок новый или старый маркер бронхолегочных инфекций? Атмосфера. Пульмонология и аллергология 2008; 4: $26-32$.

11. Flanders S.A., Stein J., Shochat G. et al. Performance of a bedside $\mathrm{C}$-reactive protein test in the diagnosis of community-acquired pneumonia in adults with acute cough. Am. J. Med. 2004; 116: 529-535.

12. Anthonisen N., Manfreda J., Warren C. et al. Antibiotic therapy in exacerbations of chronic obstructive pulmonary disease. Ann. Int. Med. 1987; 106: 196-204.

13. Stockley R.A., O'Brien C., Pye A. et al. Relationship of sputum color to nature and outpatient management of acute exacerbations of COPD. Chest 2000; 117: 1638-1645.

14. Murray P.R., Washington J.A. Microscopic and bacteriologic analysis of expectorated sputum. Mayo Clin. Proc. 1975; 50: $339-344$.

15. Clinical and Laboratory Standards Institute (CLSI). Performance standards for antimicrobial disk susceptibility tests: Approved Standard. $10^{\text {th }}$ ed. www.clsi.org/source/orders/ free/m31-a3.pdf.

16. Hurst J.R., Donaldson G.C., Perera W.R. Use of plasma biomarkers at exacerbation of chronic obstructive pulmonary disease. Am. J. Respir. Crit. Care Med. 2006; 174: 867-874.

17. Smith R.P., Lipworth B.J. C-reactive protein in simple community-acquired pneumonia. Chest 1995; 107: 1028-1031.

18. Justo D., Lachmi S., Saar N. et al. C-reactive protein velocity following antibiotics in patients with chronic obstructive pulmonary disease exacerbation and community acquired pneumonia. Eur. J. Intern. Med. 2009; 20: 518-521.

19. Weis N., Almdal T. C-reactive protein - can it be used as a marker of infection in patients with exacerbation of chronic obstructive pulmonary disease. Eur. J. Intern. Med. 2006; 17: 88-91.

20. Bircan A., Gokirmak M., Kilic O. et al. C-reactive protein levels in patients with chronic obstructive pulmonary dis- ease: role of infection. Med. Princ. Pract. 2008; 17: 202-208.

21. van Beurden W.J.C., Smeenk F.W.J.M., Harff G.A., Dekhuijzen P.N.R. Markers of inflammation and oxidative stress during lower respiratory tract infections in COPD patients. Monaldi Arch. Chest Dis. 2003; 59: 273-280.

22. Spruit M.A., Gosselink R., Troosters T. et al. Muscle force during an acute exacerbation in hospitalised patients with COPD and its relationship with CXCL8 and IGF-I. Thorax 2003; 58: 752-756.

23. Stolz D., Christ-Crain M., Bingisser R. et al. Antibiotic treatment of exacerbations of COPD. A randomized, controlled trial comparing procalcitonin-guidance with standard therapy. Chest 2007; 131: 9-19.

24. Stolz D., Christ-Crain M., Morgenthaler N.G. et al. Copeptin, C-reactive protein, and procalcitonin as prognostic biomarkers in acute exacerbation of COPD. Chest 2007; 131: 1058-1067.

25. Nuralieva G., Avdeev S., Chuchalin A. Time course of systemic inflammatory markers during acute exacerbation of COPD. Eur. Respir. J. 2007; 29 (suppl.): 555s-556s.

26. Perera W.R., Hurst J.R., Wilkinson T.M.A. et al. Inflammatory changes, recovery and recurrence at COPD exacerbation. Eur. Respir. J. 2007; 29: 527-534.

\section{Информация об авторах}

Авдеев Сергей Николаевич - д. м. н., проф., руководитель клинического отдела НИИ пульмонологии ФМБА России; тел: (495) 465-53-64; e-mail: serg_avdeev@list.ru

Баймаканова Гульсара Есенгельдиевна - к. м. н., научный сотрудник НИИ пульмонологии ФМБА России; тел: (495) 465-74-15; e-mail: gulsara. bai@mail.ru

Зубаирова Пазилат Алиевна - к. М. Н., научный сотрудник НИИ пульмонологии ФМБА России; тел: (495) 465-74-15; e-mail: zubairova @mail.ru Чучалин Александр Григорьевич - д. М. н., проф., акад. РАМН, директор НИИ пульмонологии ФМБА России; тел: (495) 465-52-64 